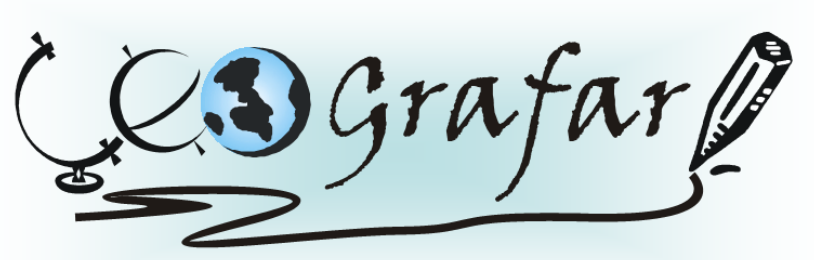

Revista Eletrônica do Programa de Pós-Graduação em Geografia - UFPR

\title{
CONVERGÊNCIAS E CONFLITOS DAS POLÍTICAS PÚBLICAS DO DESENVOLVIMENTO DO TURISMO NO ESPAÇO RURAL NAS ROTAS DO PINHÃO, REGIÃO METROPOLITANA DE CURITIBA
}

\author{
CONVERGENCE AND CONFLICTS ON PUBLIC POLICY OF TOURISM \\ DEVELOPMENT IN RURAL SPACE IN THE PINION ROUTES, IN \\ METROPOLITAN AREA OF CURITIBA
}

(Recebido em 25.10.2012; Aceito em 09.04.2013)

\author{
Marino Castillo Lacay \\ Mestre em Geografia - UFPR \\ Curitiba, $P R$, Brasil \\ e-mail:marino7489@gmail.com
}

\author{
Marcos Aurélio Tarlombani da Silveira \\ Professor Associado do Departamento de Geografia - UFPR \\ Curitiba, PR, Brasil \\ e-mail:marcos.ufpr@yahoo.com.br
}

\begin{abstract}
Resumo
O turismo rural tem sido cada vez mais utilizado como uma das ocupações não agrícolas no chamado "novo rural" e passou a formar parte das políticas públicas do desenvolvimento rural em todo Brasil. Concomitantemente, o turismo rural forma parte das políticas públicas para 0 desenvolvimento da atividade a partir dos programas de regionalização e segmentação do turismo implementados pelo Ministério do Turismo. Este artigo se propôs identificar os principais agentes envolvidos na implementação das políticas do turismo e do desenvolvimento rural na Região Metropolitana de Curitiba e o papel que exerceram na construção do turismo rural. A análise do espaço rural metropolitano apresenta elementos heterogêneos sobre a realidade econômica, social e ambiental dos municípios da Região que configuram fortes assimetrias no desenvolvimento territorial. As pesquisas de campo e as entrevistas com os agentes apontaram que boa parte das distorções e assimetrias entre municípios é reforçada pelo viés fortemente setorial dos gestores
\end{abstract}


das políticas in loco e pela falta de integração entre entidades que disputam projetos, recursos e atores. As considerações finais do trabalho destacam que, além dos vieses setoriais, a falta de articulação do planejamento e gestão das políticas públicas no espaço rural metropolitano foi resultado da limitada atuação do Estado no período.

Palavras-Chave: Região; Regionalização; Desenvolvimento; Turismo Rural; Planejamento; Políticas Públicas.

\begin{abstract}
Tourism has been increasingly used as a non-agricultural occupations within the call "new rural" becoming part of public policies for rural development. Concomitantly rural tourism is part of public policies for segment development through programs targeting the tourism regionalization and implemented by the Ministry of Tourism of Brazil MTur. This article is aiming to identify the main actors involved in the implementation of tourism policies and rural development in the metropolitan region of Curitiba and the role exerted in building metropolitan rural tourism. Analyze the metropolitan rural areas involves finding heterogeneous elements on the economic, social and environmental development of the municipalities in the region to set strong asymmetries in land. Research and interviews with the agents noted that many of the distortions and asymmetries between municipalities is strongly reinforced by the sectorial bias operating by managers policies and the lack of integration between institutions competing projects, resources and actors. The article highlights final considerations reveal that, to the period of analysis beyond these subterfuges sector, lack of joint planning and management of public policies in rural areas resulted from limited metropolitan performance.
\end{abstract}

Keywords: Region; Regionalization; Development; Rural Tourism; Planning; Public Policy.

\title{
Introdução
}

Este artigo resume o trabalho de dissertação que teve como objeto de estudo o turismo rural no desenvolvimento do espaço metropolitano, com ênfase na análise da implementação das políticas públicas na Região Turística das Rotas do Pinhão na Região Metropolitana de Curitiba - RMC, no período entre 2003 e 2010. A Região Turística Rotas do Pinhão abrange uma área de $16.578 \mathrm{~km}^{2}$, que corresponde a perto de $8,3 \%$ do território estadual, fazendo divisa com as regiões 
turísticas Litoral, Campos Gerais e Centro-Sul sendo constituída por 29 municípios ${ }^{1}$. O referido trabalho buscou analisar categorias básicas de análise capazes de expressar o fenômeno turístico na área rural metropolitana como um instrumento para o desenvolvimento, dentro da política pública do turismo e das políticas para o desenvolvimento rural, e assim entender o papel exercido pelos agentes em suas múltiplas escalas no fortalecimento da região e da regionalização do turismo.

A partir da década de 1990, o turismo rural veio a reboque das novas ruralidades que se conformaram em torno da pluriatividade na agricultura familiar (SILVA, 2000), incentivado por programas específicos no Estado (COMEC, 1996). Os processos de esvaziamento demográfico do campo, a proletarização da mão de obra e a diminuição da participação da agricultura no Produto Interno Bruto-PIB (FERREIRA, 1999) levaram muitas instituições de pesquisa e centros acadêmicos a enxergar esses fatos como o fim da pequena produção familiar no Brasil. No caso específico da RMC, o êxodo de grandes contingentes de população, notadamente do rural para as cidades da RMC provocou o governo da época, a desenhar propostas para sistematizar o uso e a ocupação do solo no entorno geográfico e, ao mesmo tempo, promover um sistema de proteção das bacias hidrográficas que abastecem de água a metrópole (COMEC, 1978, 2006).

A análise do turismo no espaço rural da Região Metropolitana de Curitiba ilustra a relevância adquirida pela atividade ao longo dos últimos anos, como alternativa de renda nas pequenas propriedades da agricultura familiar da região, e a capacidade de incorporar mão de obra, acomodados na complementação de renda da pluriatividade. Segundo o Censo Demográfico de 2010, os 29 municípios da Região Metropolitana de Curitiba, com uma população total de 3.223 .836 habitantes, representam $30,8 \%$ da

\footnotetext{
${ }^{1}$ Este artigo usou indistintamente como equivalente o nome Rotas do Pinhão e Região Metropolitana de Curitiba - RMC. A Região Metropolitana de Curitiba está quase totalmente localizada no Primeiro Planalto Paranaense composta pelos municípios de Adrianópolis, Agudos do Sul, Almirante Tamandaré, Araucária, Balsa Nova, Bocaiúva do Sul, Campina Grande do Sul, Campo do Tenente, Campo Largo, Campo Magro, Cerro Azul, Colombo, Contenda, Curitiba, Doutor Ulysses, Fazenda Rio Grande, Itaperuçu, Lapa, Mandirituba, Piên, Pinhais, Piraquara, Quatro Barras, Quitandinha, Rio Branco do Sul, Rio Negro, São José dos Pinhais, Tijucas do Sul e Tunas do Paraná. A RMC apresenta como principais divisores naturais geográficos; a sudoeste a Serra da Escarpa Devoniana, alcançando as bordas do Segundo Planalto Paranaense, e a leste a Serra do Mar, divisor com a planície litorânea. Faz fronteira ao norte com o Estado de São Paulo e ao sul com o de Santa Catarina. Mais detalhes sobre as Rotas do Pinhão, consultar SETU (2008), Plano Estratégico de Desenvolvimento do Turismo Regional 2008-2011 em: http://www.setu.pr.gov.br/ arquivos/File/Planos/PlanoRotasdoPinhaoCuritibaeRegiaoMetropolitana.pdf
} 
população urbana do Estado do Paraná. A RMC apresenta contrastes que combinam o aglomerado urbano mais importante do Estado (Curitiba) com os municípios de maior pobreza (Vale do Ribeira). Desses habitantes, 2.9 milhões estão nas cidades, que representam uma taxa de urbanização de 92\%. Houve uma combinação de espacialidades socialmente críticas com outras de extrema relevância econômica e institucional; entre seus municípios, houve alguns com elevado grau de desenvolvimento enquanto outros caminharam para descobrir a sua vocação (IPARDES, 2004). $\mathrm{Na}$ década de 1991-2000, o crescimento da população da RMC foi acima de $3 \%$, enquanto nos últimos dez anos, entre 2000 e 2010, a taxa diminuiu para 1,36\% (IPEA, 2011).

Entre outros objetivos procurou-se identificar o papel desempenhado pelo turismo rural quanto oportunidade para o desenvolvimento de pequenos produtores rurais na RMC. Partiu-se da tese sustentada por alguns autores (ALMEIDA e RIEDL, 2000; SILVEIRA, 2009) de que a defesa do segmento não pode ser encarada como panaceia do desenvolvimento, em localidades onde nenhum outro segmento econômico é capaz de produzir excedente econômico para a reprodução do capital. Essa relação não é possível ser generalizada como uma verdade tautológica na RMC, onde o rural e sua relação com o espaço regional assume contornos mais complexos de fragmentação, heterogeneidade e desigualdade (BRANDÃO, 2009) por isso a gestão institucional, o desenvolvimento de modelos de gestão local e a formatação de produtos não garantem individualmente o desenvolvimento de mercados turísticos, como base para o desenvolvimento da atividade na região.

O alcance dos objetivos a que os processos de desenvolvimento se propõem, está relacionado ao empoderamento dos atores que se apropriam e atuam sobre o território, e isso se dá em diferentes escalas, o que é definido por Brandão (2007) como ação transescalar. O desenvolvimento deve ser visto como um conjunto de ações, mecanismos, estratégias e políticas endógenas, desencadeadas por atores locais-regionais em interação com as demais escalas de poder e gestão, reforçando e constituindo articulações por meio de novos usos políticos e econômicos do espaço regional.

É nesse cenário de multidimensionalidade de agentes, atores da cadeia produtiva e escalas que se analisou a Região Turística Rotas do Pinhão onde foram identificados diversos tipos de comportamentos de gestão e de mercado na atividade da 
cadeia produtiva do turismo (IPARDES, 2008, 2008a), estabelecendo relações diretas e configurando o espaço regional complexo e diversificado.

Como objetivo geral foi proposto a caracterização da relação entre turismo, políticas públicas e o desenvolvimento na Região Metropolitana de Curitiba (Região Turística - Rotas do Pinhão), a partir da análise das ações implementadas da política de regionalização para o turismo rural no Estado do Paraná.

Como desdobramento do objetivo geral, foram traçados os seguintes objetivos específicos:

1. Em primeiro lugar, analisar e avaliar a produção e as práticas de desenvolvimento do turismo rural por meio das políticas públicas setoriais do Ministério de Desenvolvimento Agrário - MDA, e do turismo rural do Ministério do Turismo - MTUR, a visão dos agentes nas escalas estadual e municipal, e a identificação dos pontos de convergência e fragilidade no desenvolvimento da regionalização do turismo rural nas Rotas do Pinhão na $\mathrm{RMC}$;

2. Em segundo lugar, decompor a implementação das políticas públicas para o turismo rural e das práticas na RMC a partir da visão dos agentes nas escalas federal, estadual e municipal, e conhecer o papel que os agentes exerceram no incentivo à pluriatividade por meio das políticas públicas setoriais do meio rural e do turismo. $\mathrm{E}$,

3. Em terceiro lugar, identificar o papel do Estado e dos agentes regionais no turismo rural das Rotas do Pinhão, o papel das escalas de participação e o processo de regionalização à luz do desenvolvimento (territorial) mediante as práticas de turismo rural.

As hipóteses de trabalho buscaram focalizar principalmente o papel dos agentes do processo e a influência que estes tiveram na forma de implementação das políticas públicas para o turismo rural na região turística Rotas do Pinhão. $\mathrm{Na}$ produção e implementação das políticas públicas para o turismo rural por parte dos agentes federais, estaduais e municipais, não houve integração dos objetivos pautados para o desenvolvimento rural, mas tampouco para o desenvolvimento do turismo no espaço rural. 


\section{Área de estudo: aspectos relevantes da localização da região turística Rotas Do Pinhão na Região Metropolitana de Curitiba}

Para evitar conflitos de entendimento com a nomenclatura territorial definida pelo IBGE e amenizar a tarefa analítica, quando denominada, a região metropolitana de Curitiba com seu núcleo central foram chamados indistintamente de região; região turística foi denominada aquela que composta pelos 29 municípios da RMC cujo nome para efeitos do mercado de produtos turísticos é Rotas do Pinhão. A região turística Rotas do Pinhão contem a indicação para os circuitos turísticos e municípios que participam ativamente do processo de construção das Rotas do Pinhão. (MAPA 1)

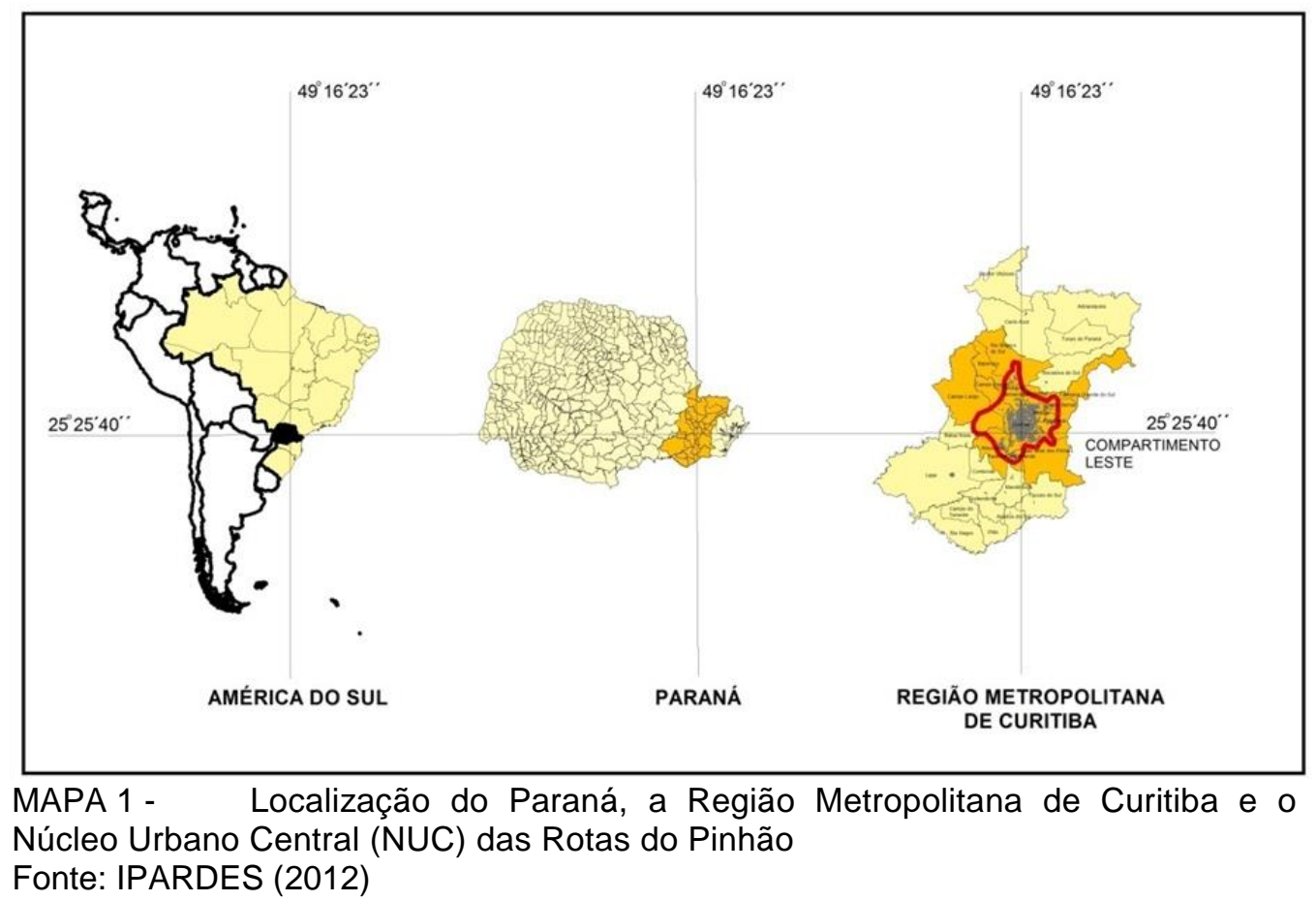

O Fórum metropolitano é reconhecido como a governança que congrega os municípios atuantes na Rotas do Pinhão. É um fórum público que em tese, congregaria os 29 prefeitos municipais (e/ou seus secretários de turismo) e sendo equivalente à Rotas do Pinhão e a divisão administrativa do IBGE da RMC, mas que na prática não funciona como regimentado (LACAY, 2012) . 


\title{
Marco teórico do estudo
}

\section{A construção do marco de referencia teórica do estudo descansa sobre o tripé}

\begin{abstract}
dos conceitos de região, do desenvolvimento e da política pública, para os quais se dedicou uma exaustiva revisão bibliográfica de autores, que se apresenta no quadro 1,
\end{abstract} resumidamente:

QUADRO 1- Marco Teórico da Pesquisa

\begin{tabular}{|c|c|c|}
\hline $\begin{array}{c}\text { REGIÃO, } \\
\text { REGIONALIZAÇÃO } \\
\text { E REGIONALIZAÇÃOO NO } \\
\text { PARANA } \\
\end{array}$ & $\begin{array}{l}\text { DESENVOLVIMENTO (regional), } \\
\text { DESENVOLVIMENTO RURAL E RURALIDADE }\end{array}$ & $\begin{array}{c}\text { POLITICA PÚBLICA } \\
\text { PROCESSO, IMPLEMENTAÇÃO E } \\
\text { A POLITICA PUBLICA TURISMO } \\
\text { RURAL NA RMC }\end{array}$ \\
\hline $\begin{array}{l}\text { Região como conceito e região } \\
\text { como objeto de planejamento, a } \\
\text { regionalização espacial, e a } \\
\text { regionalização do programa de } \\
\text { Ministério do Turismo } \\
\text { (regionalização turística: atrativos, } \\
\text { produtos e roteiros) os seus } \\
\text { resultados na implamentação do } \\
\text { programa de regionalização do } \\
\text { turismo no Parana e na RMC }\end{array}$ & $\begin{array}{l}\text { Conceito do Desenvolvimento, Municípios rurais e } \\
\text { urbanos. Caracterização e elementos do } \\
\text { Desenvolvimento (regional, local, endógeno). O } \\
\text { Desenvolvimento rural e os elementos que } \\
\text { destacam o turismo rural. As diversas } \\
\text { interpretações do rural e a interação com o urbano: } \\
\text { de oposição, de complementação, de } \\
\text { subordinação. A ruralidade como elemento principal } \\
\text { do rural. O resgate de elementos rurais para o } \\
\text { turismo rural na RMC. }\end{array}$ & $\begin{array}{l}\text { O que constitui a política pública, a } \\
\text { construção do processo da política } \\
\text { pública, o ciclo de implementação da } \\
\text { política pública. As escalas de } \\
\text { implementação da política pública, } \\
\text { os agentes e os atores no processo } \\
\text { de implementação. os embates entre } \\
\text { escalas e políticas: turismo rural } \\
\text { como parte da política pública do } \\
\text { desenvolvimento rural ou do } \\
\text { desenvolvimento do turismo. } \\
\text { Repercussão entre os agentes } \\
\text { implementadores das políticas na } \\
\text { RMC. }\end{array}$ \\
\hline $\begin{array}{l}\text { Debates sobre Região: Gomes } \\
\text { (2007); Lencioni (2009); Carleial } \\
\text { (1993); Diniz e Lemos (2005); Egler } \\
\text { (2007); Furtado (1983,2000,2002); } \\
\text { Cunha (2009); Heidrich (2000); } \\
\text { Bahl (2004); Pearce (2003); Cruz } \\
\text { (1998, 2000, 2005, 2007, 2010); } \\
\text { Silveira (2002, 2009); Fratucci } \\
\text { (2008). } \\
\text { Sobre a Regionalização: George } \\
\text { (1978); Gomes(2007); Correa } \\
\text { (1987); Heaesbaert (2005); Correa } \\
\text { (1986), Gomes(1988,1995), } \\
\text { Lencioni (1999) e Heaesbaert } \\
\text { (1988,1999,2003), Limonad (2004); } \\
\text { Limonad, Heasbaaert e Moreira } \\
\text { (2004). Sobre a Região e } \\
\text { regionalização no Paraná - } \\
\text { Magalhães, Kleinke (2000), Padis } \\
\text { (2006); Fajardo, 2008); Região } \\
\text { turística ver MTUR (2004) .Setu } \\
\text { (2006); }\end{array}$ & $\begin{array}{l}\text { Desenvolvimento ver Furtado (1983,2000,2002); } \\
\text { Boisier (1995, 1996, 1999, 2001, 2005), Arocena } \\
\text { (2001), Vazquez Barquero (2000), Albuquerque et } \\
\text { alii (2002); Brandão (2005, 2007).Moura (1998a, } \\
\text { 1998b,2003,2009) } \\
\text { Desenvolvimento rural, ruralidade e turismo } \\
\text { rural, ver também: Schneider (2008), Kageyama, } \\
\text { (1999, 2008). IICA (2005, 2008) FAO(1994, 2000); } \\
\text { Terluin (2003 APUD KAGEYAMA,2008,) Ellis e } \\
\text { Bigs, (2001, apud ALVES \& GUIVANT, 2010); } \\
\text { Veiga (2002) Abromovay (2003; 2006). Fajardo } \\
\text { (2008); Favaretto(2010); Graziano da Silva e } \\
\text { Campanhola (2000),Graziano da Silva (2001); } \\
\text { Graziano da Silva e del Grossi(2002) Mattei(2003, } \\
\text { 2004); } \\
\text { Estudos da Ruralidade ver Carneiro (2000); } \\
\text { Ferreira(1999); Wanderley (1997;1999;2000); } \\
\text { Bazoti e Pereira (2010). } \\
\text { Do Turismo Rural ver Portuguez(1999, 2001, } \\
\text { 2005), Tulik(1997; 2003; 2010), Rodrigues (2000), } \\
\text { Santos e Pires (2010), Santos e Souza (2010); } \\
\text { Seabra(2007); Almeida e Reidl } \\
\text { (2000),Cavaco(1996);Etges(1998);Zimerman } \\
\text { (1996); Yázigi (2003,2009) }\end{array}$ & $\begin{array}{l}\text { Na Formulação e implementação } \\
\text { de políticas publicas ver: Draibe } \\
\text { (1988); Rua(1998), } \\
\text { Souza(2003,2006), Faria (2005); } \\
\text { Frey (2000), Arretche(1999), } \\
\text { Lazzaroti } \\
\text { (2004); Cruz e Sanzolo (2003); } \\
\text { Beni(2006); MTUR (2004); Sarti e } \\
\text { Coutinho (2005); } \\
\\
\text { Do Desenvolvimento rural e do } \\
\text { turismo no espaço rural ver } \\
\text { Graziano e Campanhola (2000). } \\
\text { Mattei(2004);Santos e Pires (2010) } \\
\\
\text { Do Turismo rural na RMC ver } \\
\text { também Candiotto (2010); COMEC } \\
\text { (1978, 2006); Corona(2006, 2010), } \\
\text { ECOPARANA (2006, 2008) } \\
\text { IPARDES (2008), MTUR (2004), } \\
\text { SETU (2006, 2008); Nascimento e } \\
\text { Beltrão (2004) Silveira (2001,2009), } \\
\text { Teles (2011);Nitsche (2007, 2010); } \\
\text { Nitsche e Szuchman (2004) }\end{array}$ \\
\hline
\end{tabular}

Fonte: LACAY, M. (2012) 
Os conceitos de Região, da Regionalização, do Desenvolvimento, do Desenvolvimento Rural (Novo Rural e pluriatividade),da ruralidade e do Turismo Rural, serviram para delimitar as problemáticas (arenas) num enfoque neoinstitucionalista. Foi salientada a importância da formulação e da implementação da política pública (policy cicle) e que serviram de base para a definição das políticas de regionalização do turismo (referências normativas e linha do tempo), e as políticas públicas de desenvolvimento rural (Top Down / Bottom up) que foram aplicadas na organização do espaço turístico rural da RMC, com a criação da Rotas do Pinhão.

O confronto na organização das agendas de trabalho das políticas do desenvolvimento rural e das políticas públicas do turismo rural entre as diversas instituições e escalas do setor público permitiu entender as contradições criadas pela agendas dessas políticas na RMC. O processo de descentralização das políticas e a convergência e conflitos inerentes da atuação na RMC se estruturou com a análise do papel das instituições e dos agentes (SETU/ECOPARANA; EMATER/SEAB; SEBRAE, prefeituras municipais); as escalas de atuação e implementação das políticas públicas e a implementação de Políticas Públicas contribuíram para reforçar as assimetrias e heterogeneidades, hierarquias e especializações presentes no espaço regional metropolitano (Brandão, 2009).

Ao fazer referência à regionalização (Quadro 1), privilegiou-se o uso da divisão espacial designada pela Secretaria de Estado de Turismo - SETU, onde, segundo classificação realizada em 2006 adotada pelo programa de regionalização turística no Estado, o Paraná tem dez regiões. Coincidentemente, a região turística Rotas do Pinhão corresponde aos municípios da Metropolitana de Curitiba de hoje com 29 municípios. Os vinte e seis municípios que, em 2006, compunham a RMC definida pelo IBGE, tal como legalmente instituída, já incorporava a época outros três municípios não metropolitanos (Campo do Tenente, Rio Negro e Piên). Com a entrada desses três municípios para a RMC, a região turística Rotas do Pinhão e a RMC adquirem a mesma identidade espacial. Diante isso, decidiu-se trabalhar todos os dados da RMC e, na pesquisa de campo, restringir-se ao Núcleo Urbano Central da RMC oficial, perfazendo, no total, treze unidades regionais de análise.

Como afirma Silveira (2009) outro papel da regionalização turística tem sido utilizá-la na tentativa de reduzir as desigualdades econômicas e sociais existentes 
entre diferentes localidades que integram uma mesma região de destino dentro de uma perspectiva sustentável. No entendimento de Pearce $^{2}$ (1991 apud SILVEIRA, 2009) com a regionalização busca-se obter uma maior equidade territorial através de uma melhor distribuição dos benefícios econômicos advindos do turismo, e que resulte na criação de oportunidades de emprego e geração de renda para as populações locais, e na difusão de práticas relacionadas à conservação do meio ambiente.

A regionalização do turismo, na proposta da política pública nacional dos documentos denominados Diretrizes Políticas e Diretrizes Operacionais do referido programa (BRASIL, 2004a, 2004b), propõe a noção de que o turismo é um subsistema inserido em um sistema social maior. Outro elemento adicional para análise foi o documento oficial do MTUR (BRASIL, 2004a) onde se enfatizava que a regionalização turística não deveria pautar-se nas tradicionais divisões geográficas. Assim, no âmbito do referido programa, a regionalização foi entendida como "[...] a organização de um espaço geográfico em regiões para fins de planejamento, gestão, promoção e comercialização integrada e compartilhada da atividade turística." (BRASIL, 2004a, p.11).

Contudo, a avaliação que se fez a posteriori mostrou discrepâncias entre os pressupostos teóricos que orientaram a formulação da política nacional e a sua execução nos estados do Brasil (BRASIL, 2010) e sua aplicabilidade nas diversas regiões turísticas no Estado do Paraná, em particular na Rotas do Pinhão.

\section{Metodologia}

Como método de estudo foi adotado o estudo de caso com análise exploratória do processo de desenvolvimento do turismo rural na RMC, buscando identificar os instrumentos utilizados na implementação das políticas públicas e convalidados através de pesquisa quantitativa e qualitativa sendo realizadas nas seguintes etapas:

Análise Comparativa de dados. No levantamento das informações secundárias foi relevante a análise das fontes secundárias disponíveis referentes a algumas variáveis

\footnotetext{
${ }^{2}$ PEARCE, D. (1991). Tourism Today: A geographical analysis. New York/London: Longman.
} 
espaciais como: a população e migração; a infraestrutura; o sistema produtivo; os diagnósticos do Plano de Desenvolvimento Institucional (PDI) da Coordenação da Região Metropolitana de Curitiba (COMEC), os dados do censo agropecuário do Instituto Brasileiro de Geografia e Estatística (IBGE), que contribuíram na construção do ponto de partida necessário para aprofundar a análise qualitativa, o Censo Agropecuário 2006, do IBGE e as Tabulações especiais para estabelecimentos do turismo rural; a pesquisa da Cadeia Produtiva do Turismo do Estado do Paraná, para a RMC (IPARDES, 2008b) e os dados de consumo de energia elétrica na área rural - Companhia Paranaense de Energia (COPEL). Outras fontes secundárias de importância o foram os dados oficiais da Empresa de Assistência Técnica e Extensão Rural (EMATER), anos 2009 e 2010 e as informações de monitoramento do planejamento do desenvolvimento regional do turismo da Secretaria de Turismo do Estado do Paraná - SETU, que permitiu a comparação entre os anos de 2005, 2008 e 2010. Além destes, os dados da ECOPARANA e do SEBRAE contribuíram para recuperar os principais agentes envolvidos na implementação das políticas públicas e da introdução de práticas focadas na gestão do turismo entre os atores da RMC (LACAY, 2012).

Levantamento de campo. O levantamento de campo se iniciou com visita aos municípios preliminarmente demarcados com base no critério de distância dos centros turísticos. Este trabalho foi realizado em dois momentos, março e novembro de 2010, com a identificação dos elementos turísticos nos municípios contemplados na pesquisa, daí o uso dos municípios do anel central, chamado de núcleo urbano central - NUC entorno à cidade de Curitiba. As visitas permitiram analisar as condições dos roteiros turísticos.

A pesquisa quantitativa. Com questionário fechado dirigido para os extensionistas rurais que trabalharam na RMC e que estiveram envolvidos com as práticas de ocupações rurais não agrícolas, dentre elas, o turismo rural.

A pesquisa qualitativa. Foi a ultima fase do processo de pesquisa realizado mediante entrevistas com roteiros com temas comuns, chamadas de áreas de sombra, entre os distintos agentes nas diversas escalas de atuação (federal, estadual e municipal) tratando de espremer conceitos e entendimentos da realidade do turismo rural nas Rotas do Pinhão. As entrevistas aconteceram com uma pauta de análise que envolveu três grupos de variáveis(Quadro 2), dimensionadas por Cruz (2006), a 
saber: a) O modo de desenvolvimento; b) A infraestrutura e mercado (identidade local?); c) A gestão Institucional, d) escalas de atuação, e) espaço região e território.

QUADRO 2 - Velhos e novos paradigmas das políticas públicas de turismo no Brasil: proposta de trabalho com foco na RMC

\begin{tabular}{|c|c|c|c|}
\hline DIMENSÕES & $\begin{array}{c}\text { PASSADO } \\
\text { (até final dos anos 90) }\end{array}$ & $\begin{array}{l}\text { POLÍTICA Vigente } \\
\text { (2003-2010) }\end{array}$ & $\begin{array}{c}\text { HIPÓTESES DOS CONFLITOS } \\
\text { NA RMC } \\
(2003-2010)\end{array}$ \\
\hline $\begin{array}{l}\text { Desenvolvimento } \\
\text { Econômico Regional e } \\
\text { Local }\end{array}$ & $\begin{array}{l}\text { Geração de riqueza } \\
\text { (desenvolvimento econômico a } \\
\text { qualquer preço) }\end{array}$ & $\begin{array}{l}\text { Geração de emprego e renda/ } \\
\text { desenvolvimento sustentável }\end{array}$ & $\begin{array}{l}\text { Segue a política pública } \\
\text { nacional - Avaliação }\end{array}$ \\
\hline Infra-estrutura & $\begin{array}{l}\text { Criação de facilidades para a } \\
\text { implementação de infraestruturas } \\
\text { turísticas }\end{array}$ & $\begin{array}{l}\text { Implementação/melhoria de infra- } \\
\text { estrutura básica e de transporte }\end{array}$ & $\begin{array}{l}\text { Plano de desenvolvimento do } \\
\text { turismo Pr e PDITS-BID }\end{array}$ \\
\hline $\begin{array}{l}\text { Gestão institucional } \\
\text { (Política pública) }\end{array}$ & Centralização - descentralização & $\begin{array}{l}\text { Descentralização/cooperação/ } \\
\text { gestão participativa }\end{array}$ & $\begin{array}{l}\text { Segue a política pública } \\
\text { nacional - Avaliação e } \\
\text { percepção }\end{array}$ \\
\hline Mercado & $\begin{array}{l}\text { Estado passa de regulador/ } \\
\text { interventor a Liberalização/ } \\
\text { Desregulamentação }\end{array}$ & $\begin{array}{l}\text { Estado regulador (agencias)/ } \\
\text { interventor, PPP (parcerias) e } \\
\text { orçamento público (LOA, emenda } \\
\text { parlamentar) }\end{array}$ & $\begin{array}{l}\text { Segue a política nacional - } \\
\text { Avaliação e percepção }\end{array}$ \\
\hline Escala & Nacional $\Leftrightarrow$ Regional & Regional $\Leftrightarrow$ Local & $\begin{array}{l}\text { Regional } \Leftrightarrow \text { municipal vs } \\
\text { regional } \Leftrightarrow \text { territorial }\end{array}$ \\
\hline Natureza & Objeto de atração & Objeto de atração e de proteção & $\begin{array}{l}\text { Criação de produtos e roteiros } \\
\text { turísticos - O papel dos agente: }\end{array}$ \\
\hline Espaço/ Região/ Território & Palco de ações deliberadas & $\begin{array}{l}\text { Receptáculo de ações planejadas } \\
\text { (espaço-objeto) }\end{array}$ & $\begin{array}{l}\text { Conflitos na construção do } \\
\text { Território e das territorialidades } \\
\text { o papel dos atores. } \\
\text { A turistificação do espaço }\end{array}$ \\
\hline
\end{tabular}

Fonte: o autor, Adaptado de Cruz (2006, p.345)

Finalmente, nas áreas de sombra do roteiro de entrevista permitiu identificar respostas comuns para os mesmos problemas, como o entendimento dos agentes sobre os conceitos de desenvolvimento, Região, regionalização e gestão institucional, conceitos estes respondidos por todos os entrevistados (BRANDÃO, 2007). Entre os agentes entrevistados estiveram vários de diversas escalas de atuação (esferas federal, estadual e municipal) envolvidos com o planejamento, gestão e implementação das políticas públicas, ora do desenvolvimento rural, ora do turismo rural na RMC entre 1998 e 2010. (Quadro 3) 
QUADRO 3 - Agentes e instituições entrevistados, promotoras do desenvolvimento regional e local do turismo rural na RMC

\begin{tabular}{|c|c|c|}
\hline $\begin{array}{c}\text { POLÍTICAS PÚBLICAS } \\
\text { SETORIAIS E ESCALAS DE } \\
\text { ATUAÇÃO }\end{array}$ & $\begin{array}{c}\text { DESENVOLVIMENTO DA } \\
\text { AGRICULTURA }\end{array}$ & DESENVOLVIMENTO DO TURISMO \\
\hline Federal & $\begin{array}{l}\text { Ministério do Desenvolvimento Agrário - } \\
\text { MDA (entrevistado) } \\
\text { UFPR - ITCP (entrevistado) }\end{array}$ & Ministério do Turismo -MTUR \\
\hline Estadual & $\begin{array}{l}\text { Empresa de Assistência Técnica e } \\
\text { Extensão Rural - EMATER-PR } \\
\text { (entrevistado) }\end{array}$ & $\begin{array}{l}\text { Secretaria de Estado do Turismo - SETU } \\
\text { ECOPARANA (entrevistado) }\end{array}$ \\
\hline Regional /Municipal & $\begin{array}{l}\text { Coordenação da Região Metropolitana de } \\
\text { Curitiba - COMEC(entrevistado) } \\
\text { Conselho de Desenvolvimento Rural - } \\
\text { CDRs Escritório Regional da } \\
\text { Agricultura } \\
\text { Secretarias Municipais }\end{array}$ & $\begin{array}{l}\text { Associação dos Municípios da Região } \\
\text { Metropolitana de Curitiba - ASSOMEC } \\
\text { Fórum Metropolitano } \\
\text { Secretarias Municipais (selecionados e } \\
\text { entrevistados) }\end{array}$ \\
\hline
\end{tabular}

Fonte: autor. pesquisa qualitativa (2011)

Para entender melhor os diversos percalços desse processo, os atores da cadeia produtiva (empreendedores e a comunidade) foram apenas identificados sempre que necessário (IPARDES, 2008), não se adentrando na formatação dos roteiros turísticos, tampouco em como os proprietários rurais e empreendedores participaram ativamente desses roteiros turísticos (LACAY, 2012).

\section{Discussão dos resultados: politicas de turismo rural no Paraná e na RMC}

O Programa de Regionalização do Turismo do MTUR (BRASIL, 2004) da atual Política Nacional do Turismo contemplou a consecução do desenvolvimento local e regional mediante a regionalização com foco no "planejamento coordenado e participativo". Dessa forma, a proposta adotou o conceito de região turística (BRASIL, 2004) como referência espacial, na qual se inseriam os produtos turísticos, para superar a visão setorial, segmentada, unidimensional. A região é integrada ao olhar sistêmico que foca as inter-relações entre os setores (turismo e os demais), as relações entre as diferentes partes do território (dentro da mesma região) na procura de dar oportunidade de se desenvolverem em todas as partes. 
No período de análise da implementação da política pública para o turismo rural, entre 2003 e 2010 na região turística Rotas do Pinhão, considerou-se que os propósitos estabelecidos na política nacional do turismo não foram devidamente entendidos pelos agentes das políticas públicas no Estado do Paraná. O rural metropolitano passou a ter características antes próprias do meio urbano, inclusive ofertando atrativos de lazer, turismo e moradia para uma população majoritariamente urbana (GRAZIANO DA SILVA e CAMPANHOLA, 2000).

Houve no período, contudo, um descompasso entre as políticas públicas setoriais para o desenvolvimento do turismo rural, principalmente aquelas dirigidas pelo MDA para a agricultura familiar e amparadas pelo programa nacional da agricultura familiar - PRONAF e a implementação (ou não) das políticas públicas do MTUR, do turismo no espaço rural (MATTEI, 2003 apud LACAY, 2012).

Embora o estado do Paraná ter sido um dos estados pioneiros no desenvolvimento do turismo rural do Brasil, o turismo rural não obteve o crescimento esperado no período. No caso específico da Rotas do Pinhão na Região Metropolitana de Curitiba, o papel exercido pelos agentes na região turística durante o processo de consolidação das redes e roteiros e as intervenções em suas diversas esferas (escalas) na implementação da política pública do turismo rural foi pontual em ambos os casos, ficando assentadas em questões setoriais, econômicas e mantendo a desarticulação nos resultados alcançados.(PORTUGUEZ, 1999; TULIK, 2003; MATTEI, 2004; FAVARETO e VEIGA, 2007; FAVARETTO, 2010, apud LACAY, 2012).

Para fundamentar as políticas públicas de desenvolvimento do turismo no espaço rural foram desenvolvidos os conceitos de Região, Regionalização, do Desenvolvimento, do Desenvolvimento Rural (Novo Rural e pluriatividade), da ruralidade, e do Turismo Rural, delimitando as problemáticas (arenas) num enfoque neoinstitucionalista. Foi salientada a importância da formulação (policy cicle) e sendo apresentados conceitos que serviram de base para a definição das políticas públicas de regionalização do turismo (referências normativas e linha do tempo), e as políticas públicas (Top Down / Bottom up) de desenvolvimento rural que foram aplicadas na organização do espaço turístico rural na RMC. No quadro 4, a partir da proposta de Graziano de Silva e Campanhola (2000) se resumem as diferenças entre as 
concepções distintas de formulação e planejamento das políticas públicas no meio rural, centro das controvérsias e dos conflitos inerentes ao uso turístico do espaço rural.

QUADRO 4 - Características de processos de gestão das políticas públicas para o desenvolvimento rural

\begin{tabular}{|c|c|c|}
\hline CARACTERÍSTICAS & $\begin{array}{l}\text { DE CIMA PARA BAIXO } \\
\text { "TOP DOWN" }\end{array}$ & $\begin{array}{l}\text { DE BAIXO PARA CIMA } \\
\text { "BOTTOM UP" }\end{array}$ \\
\hline Princípio & Centralização/Rigidez & Descentralização/Flexibilidade \\
\hline Planejamento & Ênfase nos controles & Ênfase na negociação \\
\hline Metas & Preestabelecidas & Reformuladas passo a passo \\
\hline Processo & $\begin{array}{l}\text { Burocrático, sem estímulo à } \\
\text { participação }\end{array}$ & Construído socialmente com estímulo à participação \\
\hline Instrumento & $\begin{array}{l}\text { "Pacotes" prontos } \\
\text { Emendas parlamentares }\end{array}$ & Mobilização de experiências e do conhecimento local \\
\hline Método de Decisão & $\begin{array}{l}\text { Autoritário, atores principais são } \\
\text { externos }\end{array}$ & $\begin{array}{l}\text { Articulação de interesses com participação relevante } \\
\text { dos atores internos }\end{array}$ \\
\hline Relação com o Estado & $\begin{array}{l}\text { Mantém o clientelismo e a cultura } \\
\text { paternalista - lideranças negativas }\end{array}$ & $\begin{array}{l}\text { Aumenta o comprometimento das comunidades locais } \\
\text { para a realização e o acompanhamento das ações } \\
\text { propostas - empoderamento - O estado como agente } \\
\text { facilitador do processo de descentralização }\end{array}$ \\
\hline Implementação & Ações essencialmente setoriais & Favorece e busca ações inter setoriais e interregionais \\
\hline $\begin{array}{l}\text { Relação com o Poder Local } \\
\text { e Regional }\end{array}$ & Contraditório e excludente & Relação de cooperação, parcerias e associativismo \\
\hline Meio Ambiente & $\begin{array}{l}\text { Ação de controle e restrições de } \\
\text { caráter punitivo }\end{array}$ & $\begin{array}{l}\text { Colaboração necessária, parcerias, viabilidade local e } \\
\text { regional. Ação educacional. }\end{array}$ \\
\hline Resultados & $\begin{array}{l}\text { Macroeconômicos, eficiência e } \\
\text { eficácia do setor, competitividade. }\end{array}$ & $\begin{array}{l}\text { Diminuição das desigualdades socioeconômicas, } \\
\text { propósito de integração inter e intrarregional }\end{array}$ \\
\hline
\end{tabular}

Fonte: Adaptado de Campanhola e Graziano (2000)

Ao longo do período em análise as agendas de trabalho entre as diversas instituições e escalas se organizaram de forma pontual para a implementação das políticas do desenvolvimento rural e as políticas públicas do turismo rural na arena da RMC. Assim o processo de descentralização das políticas e a convergência e conflitos inerentes da atuação na RMC decorrentes do papel das instituições e dos 
agentes (SETU/ECOPARANA; EMATER/SEAB; SEBRAE) nas diversas escalas de atuação e implementação das políticas públicas ficou evidenciado.

As divergências e conflitos surgiram tanto dentro do desenvolvimento rural, como também dentro do desenvolvimento dos empreendimentos turísticos, mas também fora deles. Os municípios raramente aderiram passivamente às políticas propostas desde os ministérios (top down), enquanto o Estado e seus agentes privilegiaram resultados, de processos de coordenação versus o fortalecimento dos processos de cooperação entre instituições e municípios, entre agentes e entre esses e as comunidades (empreendedoras ou produtoras) (bottom up).

A organização territorial da reprodução da força de trabalho e, mais amplamente, a organização territorial da população também foram elementos que definiram o processo fragilidade da regionalização do turismo no espaço rural metropolitano. Na regionalização houve setores da população rural que não estiveram, nem estão ainda hoje diretamente ligados à produção de e para o mercado (turístico), seja pela sua integração como mão de obra formal e informal, seja pela produção de valores de uso e serviços importantes, em especial para as atividades turísticas.

Houve também peculiaridades regionais que surgiram ao longo desses anos de forma natural, mas têm se fortalecido e se diferenciado pela forma com que se articulam as relações sociais e econômicas na região. A constatação de uma fragmentação regional na construção da regionalização turística, não foi mais do que o reflexo das formas sociais e da produção que se impunham em nível regional, e para a qual a região em estudo esteve subordinada na gestão do território.

O balanço da política publica de turismo rural na Rotas do Pinhão ficou longe de uma alocação eficiente de recursos para atingir a sustentabilidade da governança regional nascendo dependente das articulações e negociações que se produziam ao redor das prioridades e partilhas do Estado com os municípios e da Metrópole com os municípios da RMC. O crescimento da atividade não foi adequado ao tamanho da expectativas regionais do mercado turístico local (GRAZIANO DA SILVA e CAMPANHOLA, 2000), tampouco direcionado na perspectiva do desenvolvimento territorial. 
As tabulações especiais dos dados relativos aos empreendimentos turísticos periurbanos e autodeclarados rurais na RMC da pesquisa da cadeia produtiva do turismo corroboram com a afirmação acima (IPARDES, 2008b). Entre os meios de hospedagem e os serviços de alimentação pesquisados no rural metropolitano, houve uma série de elementos que delinearam como se construiu uma lógica dos atores e agentes e como repercutiu nas novas territorialidades que se consolidaram com 0 processo de turistificação (KNAFOU, 2001). Os resultados apontaram para a formatação de sistemas híbridos de ocupação não agrícolas, cuja origem e destino final não são exclusivos do lugar, pois atenderam às demandas urbanas no meio rural e com sistemas de compras e vendas (de insumos) que, na maioria das vezes os beneficiários diretos dessas longas cadeias de serviços se encontravam concentrados em empresas da metrópole (rede de atacadistas e serviços especializados) (LACAY, 2012).

Para o turismo rural metropolitano foi reservado um enxoval de descontinuidades das ações, pois como bem lembra Silveira (2002) aos problemas ambientais e sociais acrescentaram-se "a ineficiência, a não efetividade e, em certos casos, a ausência das chamadas políticas públicas" tornando a região um sistema anacrônico em cujo espaço rural periurbano convivem ainda hoje muitos outros conflitos de ocupação regional (ARAUJO, 2000; HARDT, 2004; DESCHAMPS, 2004, MOURA,1998; MOURA et al., 2003, MOURA e ULTRAMARI, 1994, apud LACAY,2012).

Dados de pesquisas qualitativas realizadas junto a municípios da RMC corroboraram com a forte diferenciação regional, acúmulo de assimetrias de riqueza, produção e mercado, e posições de hierarquia que o arranjo institucional do aglomerado urbano tem reproduzido em todas as relações e que formam parte do modelo de desenvolvimento que prevalece na região administrativa, influenciando na forma em que o turismo rural é apropriado. Os dados atualizados do PIB regional comparativamente aos dados do Estado e o Censo Demográfico 2010, ajudaram a estabelecer que a implementação de qualquer política pública, inclusive as do turismo e do turismo rural, se assenta sobre a base de disparidades regionais. A RMC aglutinou no período boa parte dos municípios com maior renda do Estado, ao mesmo tempo que agregou alguns com os piores indicadores do Estado. 
Apresentaram-se outros fenômenos que reforçaram essas disparidades no turismo rural entre as que se destacaram:

1. O aumento do uso da energia elétrica rural e uso do espaço rural para acomodar atividades urbanas;

2. O aumento das segundas residências nos municípios com restrições ambientais e, mesmo naqueles em que predomina a atividade rural;

3. Uma crescente ampliação, em áreas periurbanas, de atividades de serviços do turismo como hospedagem e serviços de alimentação detectados pelos dados da pesquisa da cadeia produtiva do turismo e que induzem a pensar na mobilidade do capital em investimentos de grande e médio porte para se apropriar do espaço rural metropolitano;

4. Mudança da relevância dos agentes das políticas públicas e do foco dessas políticas de desenvolvimento do turismo no espaço metropolitano no período de análise;

5. A intervenção conjunta de instituições como a ECOPARANA e a EMATER com o MDA. O MDA por sua parte dedicou a maior parte de seu esforço em consubstanciar os Territórios da Cidadania, missão para todo o Brasil que teve para essa atividade recursos orçamentários da União;

6. No cenário metropolitano também surgiu o SEBRAE como um novo agente; em parte interessado nos empreendedores do mercado turístico regional, fortalecendo a necessidade de construir produtos turísticos no espaço rural, a imagem do que já vinha sendo feito em outros estados do Brasil.

7. Os orçamentos e balanços oficiais identificaram que os recursos apropriados de e para a atividade chamada turismo rural eram limitadíssimos, não tendo uma ação programática específica em nenhum dos órgãos. Lamentavelmente comprovou-se que o orçamento do Estado para o turismo foi o menor no período, perdendo apenas para uma secretaria especial, sem estrutura. Assim mesmo, observou-se que os investimentos em infraestrutura com exceção da energia elétrica recuaram a cada ano.

O resultado do desenvolvimento da atividade turística no espaço rural percorreu no Estado um caminho inverso da institucionalidade do turismo rural criada 
no governo federal, fortalecendo laços de dependência de recursos externos para o desenvolvimento da atividade por não alocar recursos orçamentários para 0 desenvolvimento da atividade (LACAY, 2012).

Ainda, promoveu uma espécie de movimento a favor de emendas parlamentares que a cada ano perpassava pelo desafio de conhecer quais os sistemas de distribuição de responsabilidades e/ou competências que podiam ser estabelecidos, e, quais dessas responsabilidades os deputados federais estariam dispostos a negociar em seu nome, em emendas parlamentares individuais e/ou coletivas, que atendesse a municípios do estado, nem sempre da sua base eleitoral. Contudo, as maiores fatias de emendas parlamentares do período foram destinadas aos municípios indutores do Estado (Curitiba, Foz do Iguaçu e Paranaguá).

A compreensão escalar do fenômeno turístico e do turismo rural foi uma das preocupações esboçadas nas hipóteses de trabalho. A identificação do papel exercido pelo Estado (nas suas múltiplas escalas) através do papel exercido pelos agentes foi destacado pelo resultado das pesquisas e das entrevistas realizadas com os agentes das políticas públicas.

A pesquisa quantitativa, aleatória, com questionário fechado foi dirigida para os extensionistas rurais que trabalharam na Região Metropolitana de Curitiba, que estiveram envolvidos no período de análise com as práticas de ocupações rurais não agrícolas, e dentre elas, o turismo rural. O formulário aplicado foi o mesmo aplicado em oficina pela EMBRATUR- MDA em 19993. O objetivo de reaplicá-lo foi comparar as mudanças em torno dos problemas apontados à época. Conferiu-se que, com a exceção de problemas de infraestrutura e eletrificação rural que ganharam na região uma cobertura quase total, ainda persistem na Região Rotas do Pinhão os mesmos problemas do desenvolvimento do turismo no espaço rural diagnosticados na década anterior para todo o Brasil.

As entrevistas foram realizadas entre as diversas escalas de intervenção na região, com os agentes das esferas federal, estadual e municipal envolvidos com o planejamento, gestão e implementação das políticas públicas do turismo rural na

\footnotetext{
${ }^{3}$ Em síntese, as questões levantadas na época serviram de base para construir o processo de roteirização do turismo esboçado no Programa de Regionalização do Turismo - PRT, quais sejam, envolvimento dos atores, analise de mercado, preço e comercialização; qualificação, entre outros.
} 
RMC. Destacou-se as divergências de conceitos e entendimento sobre região e desenvolvimento e as motivações para implementação do turismo rural nas Rotas do Pinhão. A análise dos processos a partir do resultado das pesquisas levou a balizar a correção das hipóteses de trabalho em torno da organização e gestão institucional das políticas públicas para o turismo rural metropolitano.

A identificação de desarticulações interagentes e intragencias, não entendimento adequado das ações e políticas implementadas, e aplicação total ou parcial das políticas de cima para baixo (Top down) sem a devida leitura das peculiaridades e estruturas da região vieram a reforçar movimentos de exclusão e isolamento de comunidades rurais.

O resultado de ambas as pesquisas indicaram a existência predominante de fragmentação das ações das políticas públicas quer seja na implementação daquelas voltadas para o desenvolvimento rural, ou bem daquelas políticas que procuraram 0 desenvolvimento do turismo no espaço rural, comprometendo o desenvolvimento da atividade turística no espaço rural.

As entrevistas entre as diversas escalas de agentes deixaram em evidência que houve falta de entendimento do que a região significa e da sua importância no desenvolvimento de valores, princípios e identidades para o turismo rural. Embora a região ser um elemento espacial vivo, esse fato foi negligenciado na estruturação de governanças, conselhos e sistemas de representação que deveriam obedecer as relações sociais e econômicas preponderantes na região e não a modelos predeterminados pelos agentes. $O$ entendimento das instituições envolvidas na implementação das políticas públicas a respeito do que significavam as regiões e o papel que estas podiam desempenhar no desenvolvimento territorial foi limitado a interpretação de um conceito administrativo. (LACAY, 2012)

No processo de pesquisa chamou a atenção o fato de a escala federal, representada pela delegacia regional do MDA no Estado, não conhecer a existência da política pública do turismo, nem ter conhecimento da lei estadual do turismo rural, e menos ainda, do programa de turismo rural no Estado. O agente apenas declarou ter apoiado atividades que julgou convenientes para o desenvolvimento rural, podendo se encontrar (ou não) o turismo dentro desse leque (LACAY, 2012). 
Coube em alguns municípios, aos técnicos extensionistas promover a participação ou não no turismo rural, e, o relacionamento com as estruturas municipais dependia de motivações pessoais, sendo um relacionamento direto com as secretarias de agricultura municipais e não com as de turismo. Já os gestores municipais do turismo esperavam uma articulação plena de seus pares e da capital, bem como dos técnicos da Emater. Em soma trabalhava-se em compartimentos estanques para o mesmo propósito e com prioridades e entendimentos(conceituais) variáveis conforme o município da região segundo levantado na pesquisa de campo.

\section{Considerações Finais}

No período analisado entre 2003 e 2010 as mudanças na descentralização das políticas públicas, em nível federal não foram acompanhadas da compreensão e de reformas na gestão e partilha das responsabilidades nas escalas estadual e municipal na implementação das políticas públicas para o turismo rural na Rotas do Pinhão na RMC. Houve, sim, um esforço de desenvolvimento do turismo e do turismo rural a partir da organização da gestão. Essa organização seguiu modelos estáticos ditados pelo MTUR, mas não condizentes com a evolução da região turística.

Como resultado, poucos foram os agentes que interagiram na região reconhecendo a região turística Rotas do Pinhão. Ela não foi percebida como uma região. Entre o primeiro desenho da regionalização turística ocorrido em 2004 e o 2010, os municípios que participaram da Rotas do Pinhão foram abordados de diversas formas, porém integrados de forma administrativa para fortalecer a construção. Dos 29 municípios treze deles nunca participaram, outros o fizeram esporadicamente e só os do núcleo urbano central se preocuparam com manter a região turística em constante atividade.

É muito provável que os problemas que enfrentavam alguns municípios tenha sido o motivo da reduzida participação, mas tem relação primeira com a diversidade, desigualdade e heterogeneidade dos municípios regionalizados, como observado e em segundo lugar, com as cobranças de resultados dos agentes de extensão rural. 
Nesse ponto, a pressão exercida pela EMATER sobre os extensionistas para se preocuparem com o aumento da produção, da produtividade, da capacidade das ocupações não agrícolas de gerar renda adicional para as famílias, num foco que é eminentemente setorial, em torno da cadeia produtiva desenhada pelos agentes extensionistas calcada encima da propriedade rural, se opõe a produção do turismo atrelada àquilo que a propriedade individual pode oferecer para a conformação em "produto turístico".

O conflito não foi exclusivo dos agentes extensionistas. Os agentes municipais do turismo, aqueles que formam parte do município nos órgãos de ordenamento turístico local (OOTs) muitas vezes desconheciam a realidade local, por falta de orientação ou por mera falta de entendimento, enfrentaram o entorno do município onde já trabalhavam, com pouco ou nenhum domínio do que acontecia no rural e sem preocupação em construir diagnósticos mais acabados sobre a realidade.

A EMATER atendeu mais de hum mil propriedades na região metropolitana durante o período de 2003 a 2010, das quais 210 mantêm atividades de turismo rural. Houve no mesmo período um número de propriedades rurais que produziu artesanato, que trabalhou com agroindústria e/ou manteve pesque e pague que na visão dos técnicos, nenhuma dessas atividades foi considerada turismo rural. A visão cartesiana limitou em mais uma fase do processo a essência de integração regional em circuitos de municípios diferentes numa proposta regional. Houve uma insistência em resolver problemas de gestão enquanto se continuou compartimentando processos, por falta de visão sistêmica.

Um dos objetivos deste artigo foi sintetizar os conflitos inerentes à aplicação das políticas públicas do turismo rural na RMC: o resultado das pesquisas apontou para identificar que o relacionamento entre as estruturas do Estado se fragilizou pela perda de princípios norteadores da atividade turística no espaço rural metropolitano.

Não houve correspondências entre às fragilidades existentes e as atitudes para superá-las. Do ponto de vista do desenvolvimento do turismo no espaço rural houve um alcance e contraste de objetivos entre agentes que resultaram em intervenções difusas na Região Turística Rotas do Pinhão.

Os resultados obtidos também apontaram poucos indícios de parcerias efetivas de cooperação incentivadas pelos agentes entre o produtor da agricultura 
familiar, entre o empreendedor urbano no meio rural e o mercado, o que tem sido repetido por todos esses mesmos agentes como um dos entraves que se interpõem ao desenvolvimento da Cadeia Produtiva do Turismo no espaço rural.

Os valores e princípios do desenvolvimento demoram muito mais para mudar do que os comportamentos, o que resulta numa ambigüidade para os agentes promotores dessa mudança. Constatou-se que o comportamento dos agentes é tradicional, obedece a uma estrutura setorial e a políticas públicas de cunho setorial, fortalecidas pelos recursos disponibilizados para sua implementação. No período houve muito mais escolhas que há 15 ou 20 anos atrás.

À estrutura setorial confrontou velhos agentes (das políticas de desenvolvimento rural) com comportamentos aparentemente modernizados pelas políticas públicas, mas que em termos de valores (princípios) em nada se diferenciaram daqueles que apenas atendiam a política agrícola setorial, o que os tornou uma fonte adicional de conflitos, um contraditório na base e na definição de prioridades calcados na produtividade e no mercado, porém desalinhados com a cooperação e associativismo que propõem as políticas. Teve ainda, no caso dos agentes extensionistas, a pressão de entrega de produtos para a empresa, medidos em resultados quantitativos de produtividade e competitividade da propriedade rural.

Surge a partir das análises precedentes a necessidade de uma estrutura de planejamento que articule os pilares da agricultura e do turismo, bem como que promova as políticas publicas razoavelmente articuladas para o turismo com recursos suficientes para que o ciclo de implementação das políticas seja concluído.

Contudo, deve-se reconhecer que o desenvolvimento local e regional do rural metropolitano não pode ser sustentado exclusivamente pela atividade turística na região e que as políticas públicas são um elemento importante, mas não suficiente para criar competitividade nos destinos turísticos. Será isso sim, parte da estratégia de primeira ordem para o setor, mas ela sozinha tampouco resolverá a questão social que o desenvolvimento rural propõe. Sofisticados projetos de turismo na área rural podem trazer dividendos para um pequeno grupo de investidores, mas altera e fragmenta a alma dos lugares (YAZIGI, 2009). 


\section{REFERÊNCIAS}

ALMEIDA, Joaquim Anécio; RIEDL, Mário (Orgs.). Ecologia, lazer e desenvolvimento. Bauru: EDUSC, 2000.

BAHL, Miguel. Agrupamentos turísticos municipais. Curitiba: Protexto, 2004.

BAZOTTI, Angelita; PEREIRA, Valeria Villa Verde Reveles. Ruralidade, agricultura familiar e desenvolvimento. Nota Técnica n.16, IPARDES, Curitiba, nov. 2010.

BENEVIDES, IRELENO PORTO. Para uma agenda de discussão do turismo como fator de desenvolvimento local. In: RODRIGUES, Adyr Balastreri. Turismo e desenvolvimento local. São Paulo: Hucitec, 2002. p. 23-41.

BENI, Mario. Política e planejamento de turismo no Brasil. São Paulo: Aleph, 2006.

BRANDÃO, Carlos Antonio. Território e desenvolvimento: as múltiplas escalas entre o local e o global. São Paulo: UNICAMP, 2009.

BRASIL. Ministério do Turismo. Programa de Regionalização do Turismo: roteiros do Brasil: diretrizes políticas. Brasília, 2004a. Disponível em:

$<$ http://institucional.turismo.gov.br/regionalizacao/arqreg/doc_download/Diretrizes_Pol \%EDticas_Programa_Regionalizacao.pdf>. Acesso em: dez. 2010.

BRASIL. Ministério do Turismo. Programa de Regionalização do Turismo: roteiros do Brasil: diretrizes operacionais. Brasília, DF: Ministério do Turismo, 2004b.

BRASIL. Turismo rural: orientações básicas. Panorama do turismo rural na agricultura familiar... MDA/TRAF? Disponível em:

<http://institucional.turismo.gov.br/mintur/br/ministerio/documentos/normas.cfm http://www.pronaf.gov.br/turismo/inicio.htm>. MTUR, 2004a. Acesso em: 2010.

ETGES, Virgínia Elisabeta. Turismo rural: uma alternativa de desenvolvimento para as comunidades rurais. In: LIMA, Luiz Cruz. Da cidade ao campo: a diversidade do saber-fazer turístico. Fortaleza: UECE, 1998.

FRATUCCI, Aguinaldo C. A dimensão espacial nas políticas públicas brasileiras de Turismo: as possibilidades das redes regionais de turismo. Tese (Doutorado) Universidade Federal Fluminense, Rio de Janeiro, 2008. Disponível em: $<$ http://www.bdtd.ndc.uff.br/tde arquivos/26/TDE-2009-05-28T131249Z2005/Publico/Agnaldo\%20Fractucci-Tese.pdf>. Acesso em: jan. 2011.

GOMES, Paulo César da Costa. O conceito de região e sua discussão. In: CASTRO, Iná Elias de; GOMES, Paulo Cesar da Costa; CORRÊA, Roberto Lobato. Geografia: conceitos e temas. Rio de Janeiro: Bertrand Brasil, 2007. 
GRAZIANO DA SILVA, José; CAMPANHOLA, Clayton. O novo rural brasileiro: uma análise nacional e regional, vol. 1 e 4. Campinas: UNICAMP - EMBRAPA, 2000. GRAZIANO DA SILVA, José; CAMPANHOLA, Clayton. Panorama do turismo no espaço rural brasileiro: nova oportunidade para o pequeno agricultor. Trabalho apresentado no Congresso Brasileiro de Turismo Rural: Turismo no Espaço Rural Brasileiro. Piracicaba: FEALQ, 1999. p.9-42.

HAESBAERT, Rogério. Regional-global: dilemas da região e da regionalização na geografia contemporânea. Rio de Janeiro: Bertrand Brasil, 2010.

IPARDES. Cadeia produtiva do turismo no Paraná estudo sobre as regiões turísticas do estado. Curitiba: IPARDES, 2008a.

IPARDES. Cadeia produtiva do turismo no Paraná síntese do estudo sobre as regiões turísticas do estado. Curitiba: IPARDES, 2008b.

IPARDES. Leituras regionais: mesorregião geográfica metropolitana de Curitiba: IPARDES, 2004

KNAFOU, Remy. Turismo e território: para um enfoque científico do turismo. In: RODRIGUES, Adyr A. Balastreri et alii. (Org.). Turismo e geografia: reflexões teóricas e enfoques regionais. São Paulo: Hucitec, 2001.

LACAY, Marino C. Convergências e conflitos das políticas públicas do desenvolvimento do turismo no espaço rural na Rotas do Pinhão, Região metropolitana de Curitiba. Dissertação (Mestrado em Geografia) - Universidade Federal do Paraná, Curitiba. Maio 2012.

LIMONAD, Ester; HAESBAERT, Rogério; MOREIRA, Ruy (Orgs.). Por uma nova regionalização: agentes, processos e escalas. São Paulo: Max Limonad, 2004.

MOURA, Rosa; MAGALHÃES, Marisa Valle. Leitura do padrão de urbanização do Paraná nas duas últimas décadas. Revista Paranaense de Desenvolvimento, Curitiba, n.88, p.3-21, maio/ago. 1996.

MOURA, Rosa; ULTRAMARI, Clóvis. Metrópole: grande Curitiba: teoria e prática. Curitiba: IPARDES, 1994.

PARANA. COMEC. Plano de Desenvolvimento Integrado. Documento para discussão, 2001.

PARANÁ. COMEC; EMATER/PR; ECOPARANA. Região metropolitana de Curitiba. Documento-proposta sobre o Anel de Turismo da RMC. 2000.

PARANÁ. EMATER; COMEC. Turismo em áreas rurais. Ago. 1999a. 
PARANÁ. EMATER; SEMA/Colombo. Programa da UFPR de desenvolvimento do Vale do Ribeira: saúde, educação e desenvolvimento rural. 1999. Disponível em: $<$ http://www.valedoribeira.ufpr.br/turismosustentavel.htm>. Acesso em: 2006. PARANÁ. Lei Estadual n. ${ }^{\circ} 15.143$ de 31 de maio de 2006. Define as atividades turísticas que especifica, como atividades de "Turismo Rural na Agricultura Familiar". Disponível em: <http://www.redetraf.com.br/r-legislacao-lei-15143.asp>. Acesso em: jul. 2008.

PARANÁ. SETU - Secretaria de Estado do Turismo do Paraná. Programa de Regionalização do Turismo no Estado do Paraná. Oficina do Plano Estratégico de Desenvolvimento Turístico Regional - Curitiba, 25 abr. 2008. Disponível em: $<$ http://www.arquivos.setu.pr.gov.br>. Acesso em: maio 2008.

PARANÁ. SETU - Secretaria de Estado do Turismo do Paraná. Programa de Regionalização do Turismo no Estado do Paraná. Oficina do Plano Estratégico de Desenvolvimento Turístico Regional - Curitiba, 25 abr. 2008. Disponível em: $<$ http://www.arquivos.setu.pr.gov.br>. Acesso em: jun. 2010.

PORTUGUEZ, Anderson P. Agroturismo e desenvolvimento regional. São Paulo: Hucitec, 1999.

SANTOS, A.; PIRES, Paulo dos Santos. Políticas públicas de turismo rural: uma alternativa necessária. In: SANTOS, Eurico de Oliveira; SOUZA, Marcelino de (Orgs.). Teoria e prática do turismo no espaço rural. São Paulo: Manole, 2010.

SCHNEIDER, Sergio. A pluriatividade na agricultura familiar. 2.ed. Porto Alegre: UFRGS, 2008.

SILVEIRA, Marcos Aurélio Tarlombani da. Turismo e transportes na região metropolitana de Curitiba e litoral do Paraná: elaboração de subsídios para o aumento da capacidade competitiva do Sistema de Transportes regional. Projeto de Pesquisa: Departamento de Geografia/UFPR/FUNDAÇÃO ARAUCÁRIA. Curitiba, 2008.

SILVEIRA, Marcos Aurélio Tarlombani da. Turismo y Sustentabilidad Entre el discurso y la acción. Revista Estudios y Perspectivas en Turismo, v.14, p.222-242, 2005.

SILVEIRA, Marcos Aurélio Tarlombani da. Turismo, políticas de ordenamento territorial e desenvolvimento: um foco no estado do Paraná no contexto regional. Tese (Doutorado) - FFLCH/USP, São Paulo, 2002.

SILVEIRA, Marcos Aurélio Tarlombani da. Turismo, políticas territoriais e estratégias recentes de desenvolvimento regional no Brasil: uma aproximação ao tema. Revista Turismo e Desenvolvimento, São Paulo, v.1, n.2, 2001 a. 
TELES, Margarete Araújo. Turismo, ordenamento territorial e desenvolvimento na região metropolitana de Curitiba. Tese (Doutorado) - Programa de PósGraduação em Geografia, Setor de Ciências da Terra da UFPR, Curitiba, 2011. TULIK, Olga. Do conceito às estratégias para o desenvolvimento do turismo rural. In: RODRIGUES, Adyr Balastreri (Org.). Turismo e desenvolvimento local. São Paulo: Hucitec, 1997.

TULIK, Olga. Turismo rural. São Paulo: Aleph, 2003. (Coleção ABC do Turismo).

VEIGA, José Eli da. A dimensão rural do Brasil. FEA-USP. Programa de Seminários Acadêmicos. 2004a. Disponível em: $<$ http://www.econ.fea.usp.br/seminarios/artigos/dimensao rural.pdf >. Acesso em: dez. 2011.

VEIGA, José Eli da. Cidades imaginárias: o Brasil é menos urbano do que se calcula. São Paulo: Autores Associados. 2002

YAZIGI, Eduardo. A alma do lugar. São Paulo: Contexto, 2009.

ZIMMERMANN, Adonis. Turismo rural: um modelo brasileiro. Florianópolis: do Autor, 1996. 